\title{
Sustainable Development Practices in the Moroccan Small and Medium Enterprise: by What Means and for What Purpose?
}

Keltoum Rahali ${ }^{*}$, Abdelaziz Chaouch $^{1}$, Elmahjoub Aouane ${ }^{2}$, Sami Chbika ${ }^{2}$, Abderrazzak Khohmimidi ${ }^{3}$, Mustapha Kouzer ${ }^{1}$, Abdellatif Elouali ${ }^{3}$

${ }^{1}$ Department of Chemistry, IBN TOFAIL University, Kenitra, 14000, Morocco

${ }^{2}$ Department of Biology, IBN TOFAIL University, Kenitra, 14000, Morocco

${ }^{3}$ Sciences of Management, Mohamed V University, Rabat, 10090, Morocco

A R T I C L E I N F O

Article history:

Received: 24 July, 2020

Accepted: 23 August, 2020

Online: 05 October, 2020

Keywords:

Management

SME

Sustainable development

\begin{abstract}
A B S T R A C T
The objective of this article is to highlight the relationship between the integration of sustainable development practices in Moroccan Small and Medium Enterprises (Smes) and the challenge sought by managers in order to ensure competitiveness and sustainability. Indeed, present-day Smes are operating in a world where economic, social, societal or environmental constraints are constantly evolving. The Sme has to face, on a daily basis, new challenges such as economic stability and sustainability alongside the major structures because the challenge of any company is to be able to differentiate itself by adding its own trace promoting a more stable positioning in a fairly hostile environment. The investigation is carried out on a sample 30 Smes in the city of Kénitra due to the importance that this city holds in terms of both geographical dimension and economic inputs on the regional scale, $13.6 \%$ of the jobs generated by the SME according to the report of the high Planning Commission (HCP 2017). The results obtained reveal that the major concern of the managers of the Moroccan Sme is a purely commercial concern and that the integration of the various practices related to sustainable development in their managerial vision is only a means and does not constitute an objective to ensure the expected survival and sustainability.
\end{abstract}

\section{Introduction}

Most of the researches on Sustainable Development (SD) were focused, for the majority of them and until recently only on large structures. That being said, we believe that our study on Smes will be very useful as it provides us with the opportunity to analyze the means deployed by managers and the objective sought through the integration of sustainable development practices. In fact, Ashton, Russell and Futch [1] find that the majority of Smes in the United States of America are driven primarily by cost and competitiveness concerns, rather than by the implementation of green practices in their managerial practice. It is, in this sense, the merits of this study that will allow us to touch the why of the Why the integration of sustainable development practices in Moroccan Small and Medium Enterprise and by what means?

In [2], the author found that Smes represent approximately $90 \%$ of international organizations, Bank Al Maghreb identified a percentage that is close to $95 \%$ [3] with a $50 \%$ contribution to job creation, a rate which is very significant at national level. It

*Keltoum RAHALI, IBN TOFAIL University Kenitra, +212676975725, rahkel@hotmail.fr should be noted that these structures also play a significant role in negatively impacting their environment [4]-[6]

Indeed, all the literature research shows that Smes, by their rather particular features, translate differently the integration into their systems of management of Sustainable Development (SD) practices than large structures i.e. often working in a different way in terms of their involvement in this process. Although the term of sustainable development is differently defined by several authors, we have retained the Brundtland's report definition (1987) "Our Common Future" [7] which defines it as a development that must meet the needs of the present without compromising the ability to meet those of future generations. This is not about stopping economic growth, on the contrary."

It is with this in mind that our investigation focused on the concern behind the introduction of this concept of SD through all its facets (certification, social responsibility, societal responsibility, green projects, etc..) within the company as well as the means used by managers in terms of environmental management and training to establish and convey their SD culture in their managerial vision. A vision that positions 
commercial concern as a priority sought through these SD practices.

The aim is to present the results of an investigation that was carried out in the city of Kénitra, a city possessing considerable assets giving it a place and a promising situation in the new regionalization. Our approach will show a methodological approach with a presentation of the main results we have achieved.

\section{Methodology}

We opted to conduct this investigation for a quantitative study through the development of different headings that fed our questionnaire in order to approach the well-basis on the perception and adoption of the multiple practices of sustainable development in management that aims at corporate citizenship in order to clarify the why of the implementation of this model in Smes operating in the city of Kénitra. We pre-tested our questionnaire on a sample of 5 Managers operating within Smes and 4 university teachers-researchers in the field of sustainable development to check its fluidity, the flow of questions, the respondent's understanding of all the sections of the questionnaire as well as the veracity of the answers that will allow us to obtain an overview of the concept of sustainable development and the implementation of its tools within Smes through a kind of management that we can refer to as responsible [8].

The components of this study can be summarized in the following axes:

- Identification of the SME and the manager,

- The SME managers perception of the concept of sustainable development,

- The means employed by the company to ensure its environmental and/or social involvement,

- The place of training and communication of SD practices in the managerial vision and in the integration of a culture within the SME.

For each explored axis, we matched either closed questions with the possibility of a yes or no answer, or questions with a range of answers ranging from one to several checkboxes. For more suggestions from respondents such as directors, managers, or project managers, whose functional quality is interesting, we have suggested an open question that could be used to push them forward in order to collect more information that can help us to better develop our interpretation.

We have conducted our investigation on 30 Smes (This data gathering phase coincided with the confinement). The choice is often made depending on the number of employees and turnover [9] [10]; as far as our investigation is concerned, only the workforce criterion will be used, a permanent workforce between (10 and 200) employees according to the 2002 Charter classification 1 . This classification, which corresponds to the quantitative approach, integrates two other qualitative parameters, namely its location in the kénitra region and the type of activity that is part of the industrial sector.

It is important to note that our sample includes Smes in this region whose activity is in the secondary sector, which is considered as strategic because it provides engineering jobs and research and development work for service companies of the tertiary sector [11], while focusing on the most widespread fields where technical progress remains moderate [12].

The city of Kénitra covers, according to the HCP, a total area of $3,052 \mathrm{~km}^{2}$, or $17.37 \%$ of the entire region of Rabat-SaléKénitra (RSK) which is one of the 12 regions of Morocco, created by the new territorial division of the regions of 2015 in application of the Decree No. 2-15-40 of the Official Bulletin of 05 March 2015.

Our choice has settled on this city because it benefits from an economic array that allows it to appropriate a fairly important place in terms of production and job creation in its region. Its environmental aspect allows it to own a special natural heritage that can be negatively impacted by the establishment of the Atlantic Free Zone and industrial districts (Bir Rami, ...) which are often accompanied by strong urbanization. Our sample size included 30 Smes with 10 to 200 employees who wanted to actively contribute in this survey while providing face-to-face interviews over a period of January 25 to March 30, 2020 which coincided with the confinement's end.

\section{Results synthesis}

The study population's target and the respondents' profiles: By referring to the first results we have obtained after the questionnaires' analysis, we confirm that the degree of interest of Smes in the theme of sustainable development and its perception as a concept are significant. Indeed, this observation allows us to confirm that the association of the concept with the trilogy (economy, environment, and social) represents a particular interest for Smes with $66.7 \%$ (Figure 2). This situation remains verified among all those who were interviewed, irrespective of their academic training, and the field of activity of the SME. At this level, we tackle the profile of respondents, whose specifications are inserted in Tables 2 and 3 .

As for the field of activity of Smes that we have approached, it remains diversified within the economic activity spectrum of Kénitra city and we note thus the strong weight of the construction sector with $26.6 \%$ which is explained by the strong urban activity in this city.

The second parameter that we mobilized to clarify the profile of respondents is the function of the respondent within the SME. It was found that the distribution of the population remains fairly balanced with a dominance of the executives (Project Managers) who totalize a score equal to $33 \%$; the second population is represented by the managers (of sites, factory or a management function) with $23.4 \%$ and managers operating in the quality field with a score of around $16.7 \%$.

Table 1: Field of activity

\begin{tabular}{|l|c|c|}
\hline Fields of Activity & Number & Weight \\
\hline Construction and Public Works & 8 & $26,6 \%$ \\
\hline Plastics industry & 6 & $20,0 \%$ \\
\hline Agri-Food / Agribusiness & 6 & $20,0 \%$ \\
\hline Piping and annexed equipment & 3 & $10,0 \%$ \\
\hline Lumber and Wood industry & 3 & $10,0 \%$ \\
\hline Clothing industry & 2 & $6,7 \%$ \\
\hline Metalic and mechanical industries & 2 & $6,7 \%$ \\
\hline Total & $\mathbf{3 0}$ & $\mathbf{1 0 0 , 0} \%$ \\
\hline
\end{tabular}


Table 2: The respondent's positions

\begin{tabular}{|l|l|l|}
\hline Occupation & Number & Weight \\
\hline Manager (Project supervisor) & 10 & $33,4 \%$ \\
\hline Director & 7 & $23,4 \%$ \\
\hline Quality manager & 5 & $16,7 \%$ \\
\hline Administrative manager & 3 & $10,0 \%$ \\
\hline Team leader & 2 & $6,7 \%$ \\
\hline Operations support agent & 2 & $6,7 \%$ \\
\hline Others & 1 & $3,3 \%$ \\
\hline Total & $\mathbf{3 0}$ & $\mathbf{1 0 0 , 0} \%$ \\
\hline
\end{tabular}

Taking these results into account, we can advance that sustainable development is seen as the concern of all the company's staff since the focus on this issue is shared by the different functions that structure the companies we have visited. This situation confirms the integration of horizontal management led by top management and which must be at the initiative of the environmental policy and the implementation of responsible management with the aim of defining a citizenship and responsibility SME environment with the attribute of vertical management [13] which brings together the various hierarchical levels of the company. A second factor to take into account in the identification of the respondent's level of education.

As shown in Table 3, nearly $40 \%$ of the population we surveyed has an engineering level while the remaining respondents are dispatched between different levels of training ranging from Bachelor's to MBA which explains the strong adherence of this profile to the many facets of the sustainable development at a rate of $66,7 \%$ (Figure 2) concerning the definition of this concept while linking it with its three fundamental axes: economic, environmental and social.

Table 3: The education level

\begin{tabular}{|l|l|l|}
\hline Education level & Number & Weight \\
\hline Engineer & 12 & $40,0 \%$ \\
\hline Baccalaureate & 10 & $33,3 \%$ \\
\hline Bachelor & 4 & $13,3 \%$ \\
\hline Mba & 3 & $10,0 \%$ \\
\hline Others & 1 & $3,3 \%$ \\
\hline Total & $\mathbf{3 0}$ & $\mathbf{1 0 0 , 0} \%$ \\
\hline
\end{tabular}

Based on the three dominant criteria of the Material Data Sheet (business sector, function, and level of training of the respondent), we end up with representativeness of each modality that is not null and that is ensured by a value exceeding $2 \%$. Through the heading «Perception of the term sustainable development», we want to raise the level of knowledge of this concept among respondents in order to assign it the connotation that stands against the perceived image and this through the strategic orientation and internal communication that is mobilized by the «awakened SME» to be able to highlight the interest and usefulness of a sustainable development approach within the structure.

As shown in Figure 1, the results from flat sorting, the awareness of the concept of sustainable development remains positive to the extent of $77 \%$ of the people we interviewed are familiar with the concept of sustainable development; it is necessary to deal with this percentage with caution since we had not assigned a definition to this concept but rather we propelled the spontaneous notoriety that stipulates the terminological knowledge of the concept of sustainable development without insisting on its understanding, its definition or even its axes to be set up within the company.

This awareness of the notion of sustainable development that is sometimes associated with corporate social responsibility [14] through the application of responsible management [15] by developing a vision of citizenship [16] can be acquired through internal information within the structure or through the environment or through the various media that deal with the subject especially in this era of Information and Communication Technologies (ICT) dominance.

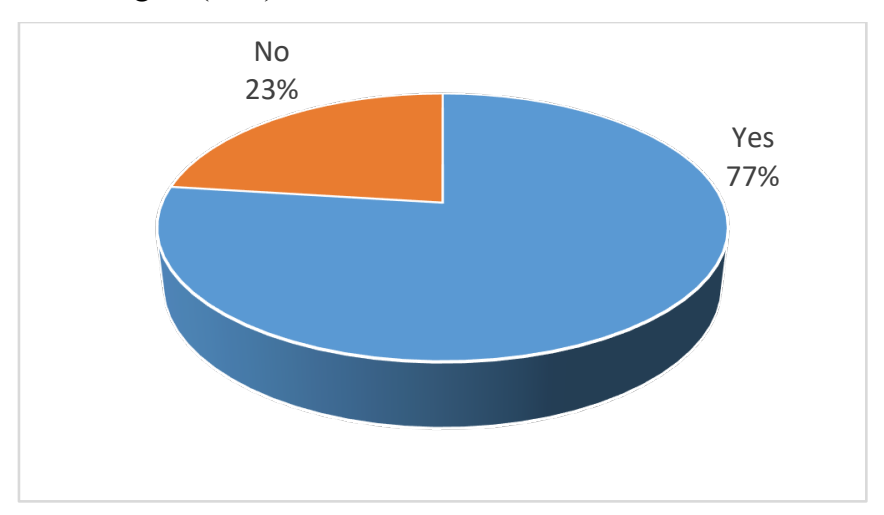

Figure 1: Sustainable development concept Notoriety

After identifying the awareness of the concept of sustainable development among the various companies that we were able to touch and whose score is of the order of $77 \%$; we were interested in delimiting the definition of this concept in the image of each SME. At first glance, as shown in Figure 2, 66\% of the population has recognized the concept of sustainable development associates it with the economic, social and environmental trilogy translated by T. Bansal [17] by the "3P" Profit, People and Planet.

Thus, SD can only be achieved through the three principles of economic efficiency, social equity and accountability; therefore, we can assume that the majority of people familiar with sustainable development have taken the time to document this concept either as a result of professional requirements or as a personal interest in the topic or in civic action since their definition falls under the common design adopted in 1987 at the Earth Summit and following the preparation of the first report of (G.H. Brundtland) which was carried out at the initiative of the United Nations and which identified the problem by associating it among other things with ecology, biodiversity and global warming...

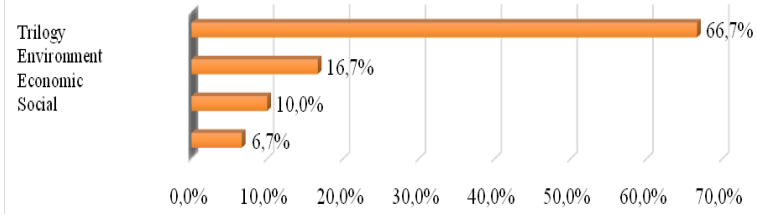

Figure 2: « Sustainable development » definition axes

Two parameters make it possible to justify the interest of the concept of sustainable development according to the perception of the respondents, namely the global necessity with 53,3\% and that stipulates the preservation of natural resources with exploitation that will not alter that of future generations and this by the setting up of equipment aimed at the use of renewable energies and also promoting the optimization of the water 
management (intelligent watering systems, featuring awareness regarding drinking water, etc.) and by adopting, each SME in its own way, responsible models to decrease the pollution that can arise during the exercise of their activities by putting in place an ecological vision within their operating method in terms of waste management, paper mining, moving more and more towards the concept of "zero paper" [18], without excluding, of course, the rationalization of their production systems.

Originating from the respondents, this vision shows their responsibility, regardless of their functions within the structure and activity they carry out. The second wave, represented by a total of $46,7 \%$, is distributed with fairly close rates and emphasizes the competitiveness and the need for the implementation of sustainable development policies that will allow them to adjust into the new economic models as they are required by globalization.

Perception and interest of the concept of sustainable development

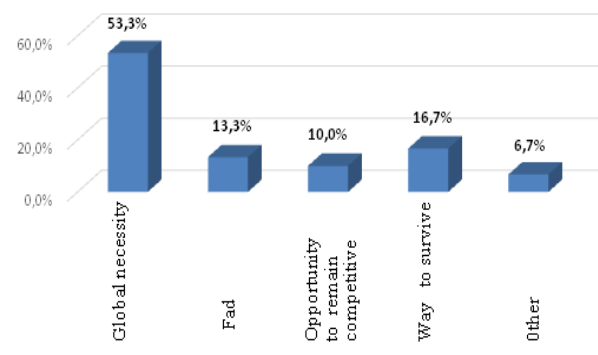

Figure 3: Perception and interest of the concept of sustainable development

\subsection{Interest and commitment of Smes in a sustainable development policy}

More than half of the Smes we interviewed, meaningly $56.7 \%$, have an environmental policy as shown in Table 4. A policy initiated within the framework of sustainable development and characterized by the foundations of responsible management. Moreover, we note that European and Canadian Smes [19] increasingly integrate management practices in favour of Corporate Social Responsibility (CSR) and are more likely to opt for certifications that are closely related to the environment or sustainable development because several studies [20] point out that SME owners claim to have started integrating sustainable development into their management practices and that $20.8 \%$ of a population of future leaders declare that they intend to do so according to the survey conducted in 2010 by the Entrepreneurship Foundation (EF). This only shows the growing commitment and involvement of Moroccan SME managers in policies stemming from sustainable development with an awareness of this concept especially following the organization of the 22nd Conference of parties held in November 2017 at Marrakech, Morocco (COP22) in Morocco.

This environmental policy is quite often associated with certification, as shown in Figure 4. Indeed, the majority of Smes with $46,7 \%$ are certified in the quality management system, which is the result of the production system, that guarantees they conquer new markets, especially foreign markets, when they post a reference to a standardization label for their production process, which ranges from the purchase of the raw material, storage, production and supply chain management. Thus, we can observe that this initiative is more a commercial requirement than an environmental one. On the other hand, the company's affiliation to a Corporate Social Responsibility certification is only $6.7 \%$ which allows us to deduce that the Social responsibility is much more a state of mind and that environmental certification, which translates into $26.7 \%$ is more sought after by the Moroccan manager.

Table 4: Existence of environmental policy within the SME

\begin{tabular}{|l|l|l|}
\hline $\begin{array}{l}\text { Existence Of An A } \\
\text { Environmental Policy In The } \\
\text { Sme }\end{array}$ & Number & Weight \\
\hline Yes & 17 & $56,7 \%$ \\
\hline No & 13 & $43,3 \%$ \\
\hline Total & $\mathbf{3 0}$ & $\mathbf{1 0 0 , 0} \%$ \\
\hline
\end{tabular}

\section{SME CERTIFICATION}

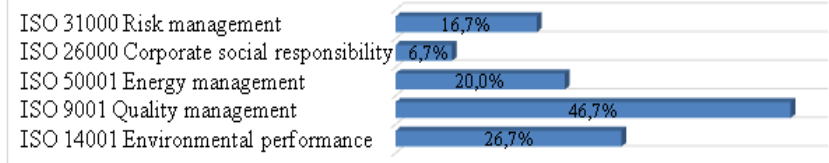

Figure 4: SME certification

Regarding the management and management methods within the SME, they must be able to lead, when implementing an environmental policy, a responsible act that aims to mobilize all staff around a collective vocation such as respect for the environment and the company's citizenship towards its stakeholders. We note in Figure 5, that the implementation of an environmental management plan is quite often the result of a $40 \%$ certification whereas the CSR approach is only $13,3 \%$, a gap that remains significant due to the level of social involvement in Smes that remains relatively small compared to large enterprises.

Sharma, S [21] points out, financial constraints of an SME as opposed to a large enterprise that is more comfortable investing in a CSR business and has the ability to absorb fixed costs and ease of access to capital and other resources. It should also be stressed that when a certification project is set up, an accompanying system is put in place to standardize all production processes, the information system, the training of teams and all staff and the production platform which must meet in a manner that complies with a specification and a requirement of the chapters of the standard in relation to the (HSE) which refers to the safety and optimization of the quality system throughout the production process; therefore, the implementation of an environmental management plan is an indispensable act in the global certification chain (ISO 9001 version 2015).

At this level, the implementation of this plan by Smes is not necessarily voluntary but rather compulsory to obtain their certification that will allow them to open up to the foreign market. This is more of a purely commercial strategic act than an awareness of respect for and protection of the environment.

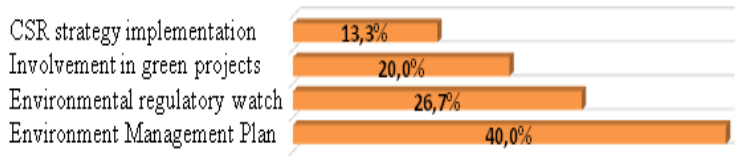

Figure 5: Management mode derived from sustainable development 


\subsection{Integration of sustainable development in the Smes managerial mode}

The operational integration of sustainable development through the adoption of a management approach that takes into account the efficient use of natural resources (Figure 6), reveals that nearly $67 \%$ of the Smes we interviewed adopt a policy that optimizes their natural resources. This figure is quite encouraging and allows us to confirm the orientation of the SME of Kénitra city towards a green economy, thus promoting the setting up of a mindset that goes in a parallel way with respect for the environment while associating economic profit of the SME with its social and environmental dimensions.

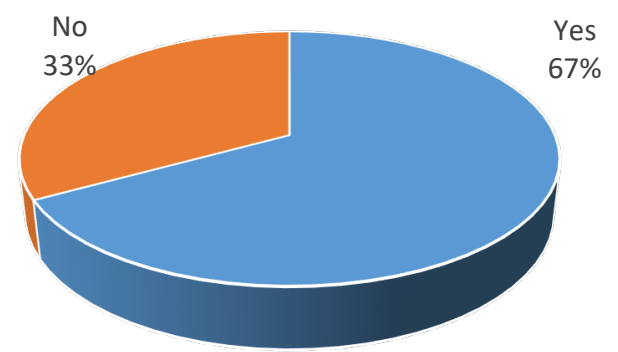

Figure 6: The efficient use of natural resources

It was necessary to stress this question, which concerns natural resources, by identifying the various means used by the SME to meet the challenge of sustainable development through the adoption of an environmental policy that must be based on the managers' actions and which represents their day-to-day activities as shown in Figure 7. It should be noted that all the answers must be stratified between the requirement of a certification process which has as its objective a commercial fact and the personal initiative which emerges more from the awareness of the mobilization and the individual commitment of everyone with regard to the environment.

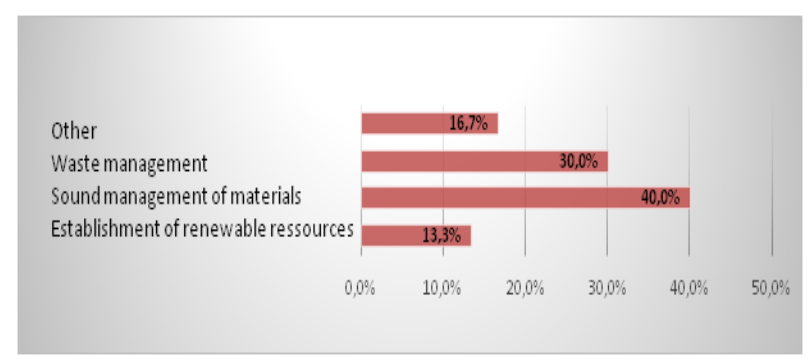

Figure 7: Means deployed to ensure efficient use of natural resources

The rational management of materials represents the largest part of the optimization of natural resources with a rate equal to $40 \%$ and which often directly impacts the decrease of the expenses of the Smes monthly bill, followed by waste management which represents $30 \%$. From this perspective, we can also deduce that the environmental policy adopted by Smes, which results in optimized management of natural resources, is more linked to the production process than to the specificity of the SME's activity. A production which, the more optimized it is, the more profit it will generate in the company's annual balance.

In addition, the implementation of renewable resources represents $13.3 \%$ although the latter allows to reduce costs considerably and to guarantee a low nuisance to the ecosystem. On the other hand, the investment cost of its implementation risks slowing down the environmental project of Smes and hinders the continuity of the sustainable development axes hoped by the manager. Through these results, we were able to highlight the importance of the implementation of environmental policy within Smes to ensure continuity, competitiveness indispensable in this era of globalization of markets especially with the outsourcing of activities from developed countries to emerging or developing countries through structures that demonstrate their support for sustainable development because the more the manager reveals its environmental involvement, the more he will gain responsible management and the more the market shares will increase. This brings us back to the fact that the implementation of this type of management requires a serious collective and individual awareness with the adoption of true corporate culture.

In the same line of thought and following the results inserted in figure 8 , which represent the contribution of sustainable development to Smes, we point out that the overall trend in responses focused on seeking a competitive advantage and minimizing costs. While the reduction of the environmental impact and the production with the eco-label that allow to model own production come last; this trend of response allows us to confirm that Smes have more a commercial concern and consider, thus, sustainable development as an opportunity to label their production process (the process most targeted by the customer) in order to be able to integrate an international standardization that guarantees their acquisition of competitive advantage [22] and a referral to all their clients, subcontractors who are, quite often, already engaged in environmental policies.

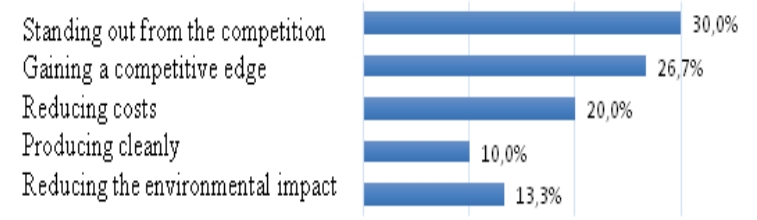

$\begin{array}{lllll}0,0 \% & 10,0 \% & 20,0 \% & 30,0 \% & 40,0 \%\end{array}$

Figure 8: Contribution of sustainable development to Smes

\subsection{The role of training and communication in the managerial perspective derived from sustainable development}

In any management system qualified as performing, staff training constitutes a crucial axis in the implementation of either environmental or social policies. In fact, this is why we found that practically all the respondents were able to take a training course which is largely in the form of a conference with $40 \%$, seminars $33.3 \%$ and internships in Morocco or abroad with respectively $10 \%$ and $16.7 \%$.

Note, for example, that according to the survey that was conducted by the association for the sustainable Development practices (Apdd) [23], SME executives attended only 50\% of conferences or seminars on sustainable development and wanted $33 \%$ more information on the various actions related to sustainable development. The observation that allows us to point out that the definition of this concept has undergone a marked evolution within the Moroccan SME which shows itself, aware of the impact of this type of training on the achievement of the goals of sustainable development as a whole. 
Table 5: Kinds of contributions to sustainable development

\begin{tabular}{|l|l|l|}
\hline $\begin{array}{l}\text { Kinds of contributions to } \\
\text { sustainable development }\end{array}$ & Number & Weight \\
\hline Conferences & 12 & $40,0 \%$ \\
\hline Seminars & 10 & $33,3 \%$ \\
\hline Symposiums & 5 & $16,7 \%$ \\
\hline Internship Abroad & 5 & $16,7 \%$ \\
\hline Internship Inside Morocco & 3 & $10,0 \%$ \\
\hline Total & $\mathbf{3 0}$ & $\mathbf{1 0 0 , 0 \%}$ \\
\hline
\end{tabular}

Nearly $40 \%$ of the population took a training course focused on environmental management, followed by responsible management with a rate of $33.3 \%$. The other topics are also related to environmental matters, such as sustainable development, the green economy and the management. The importance of these training actions is to demonstrate to what extent they enable participants to better perceive the concepts of implementing an environmental policy within the SME and to be able to customize their actions according to the sector and the process within which they operate.

It should be mentioned that our investigation has focused particularly on the themes that affect directly sustainable development while deliberately excluding the other themes that are oriented towards the Quality Management System, internal audit, communication, languages, etc. which are often planned either on the initiative of the manager or the staff.

Table 6: Sustainable development training topics

\begin{tabular}{|l|l|l|}
\hline $\begin{array}{l}\text { Sustainable Development } \\
\text { Training Topics }\end{array}$ & Number & Weight \\
\hline Environmental Management & 12 & $40,0 \%$ \\
\hline Sustainable Development & 6 & $20,0 \%$ \\
\hline Green Economy & 7 & $23,3 \%$ \\
\hline Eco-Management & 5 & $16,7 \%$ \\
\hline Responsible Management & 10 & $33,3 \%$ \\
\hline Total & $\mathbf{3 0}$ & $\mathbf{1 0 0 , 0 \%}$ \\
\hline
\end{tabular}

We conclude that the training of staff in the various topics related to the environment and Corporate Social Responsibility makes it possible to successfully integrate the practices of sustainable development within the company and therefore, increase awareness of the SME towards its social, social and environmental responsibility. This action mobilizes internal customers (the company's staff) and promotes the external SME's image towards all its stakeholders as well as its suppliers, which will enable it to evolve in terms of productivity and profitability, or its customers, which will ensure its successful positioning in an increasingly competitive market.

\section{Discussion}

The integration of sustainable development into the way of managing within Smes remains voluntary and expresses the company's commitment to its environment and stakeholders. With the emergence of this new concept that evolves in a framework marked by the economic demands that keep changing the world especially after the financial crisis of 2008, the political wave of 2011 (year of the new constitution in Morocco), the growing interest in environmental, social equity and human rights requirements; the adoption of more and more new management methods within companies and, particularly within Smes [24] who represent a significant share in the global economic weight, becomes a compulsory requirement in order to guarantee certain sustainability through the consecration of an economic asset which must be combined with environmental and social requirements. This new approach dictates that human capital is and will be for a long time to come to the cornerstone of any economy. Hence, its awareness, its training and support represents the optimal solution for Smes that want to go towards the acquisition of a sustainable competitive advantage.

Consequently, according to Torugsa, N.A [25], a social responsibility strategy can bring significant value to the market performance of an SME and can have a very significant impact on its financial performance. In addition, Lin, L et al, [26], consider that the corporate social responsibility (CSR) has presently become an essential aspect in a company's strategy and it is closely linked to its reputation because positive reputations generally lead to very positive financial results and performance.

During this survey, we were able to demonstrate that the concept of sustainable development through a few facets remains fairly well introduced within the Moroccan SME (77\%); most often associated with the quality process or certification, it converges towards the same goal, namely, increasing competitiveness, resisting new changes in world trade and establishing an opportunity for referencing with all external stakeholders [27] that are very demanding and very committed in environmental policies.

\section{References}

[1] W. Ashton et al., "The Adoption of Green Business Practices Among Small US Midwestern Manufacturing Enterprises" J. Environ. Plan. Manag. 2017.

[2] C.M. Parker et al., "A review of interventions to encourage SMEs to make environmental improvements" Environmental and Planning C, 2009.

[3] Bank-Al-Maghreb, Rapport annuel, 285p, 2013.

[4] F. Labelle et al., "la responsabilité sociétale des petites et moyennes entreprises ou la RSPME" une analyse de la littérature des dix dernières années. 2010.

[5] L. Temri, "Partage des bonnes pratiques de développement durable" le cas des PME agroalimentaires du Languedoc-Roussillon, Innovations, 1, 2009.

[6] H. Jenkins, "A critical of conventional CSR theory" An SME Perspective, journal of General Management, 29, 2004.

[7] G.H. Brundtland, "Notre avenir à tous, Commission mondiale de l'environnement et du développement, Edition du Fleuve, 1987.

[8] J.C. Dupuis, "management responsable : vers un nouveau comportement des entreprises ? La Revue des Sciences de Gestion, n 211-212, 2007. https://www.cairn.info/load_pdf.php article=rsg_247

[9] C. Blais, "Indicateur et tableau de bord de gestion : Mesure de la performance des PME en développement durable. Mémoire de maitrise, Université de Sherbrooke, Sherbrooke, 2011.

[10] K. Delchet, "Développement durable, l'intégrer pour réussir, 2007.

[11] C. Clark, Les conditions du progrès économique, Paris, P.U.F., I960. https://www.universalis.fr/encyclopedie/colin-clark/

[12] J. Fourastié, préface de l'édition du Grand Espoir du XXe siècle, 1989.

[13] S. Ghoshal, "Changing the Role of Top Management : Beyond Structure to Processes", la Harvard Business Review, 1995

[14] E. Reynaud, "Impact de la protection de l'environnement sur la gestion des coûts, Responsabilité Sociale de l'Entreprise et Performance, éd. d'organisation, Paris, 2004.

[15] R. Perez, "La revue des sciences de gestion, Direction et Gestion, n²11212- RSE, Quelques réflexions sur le management responsable, le développement durable et la responsabilité sociale de l'entreprise, 2002

[16] Turcotte et al, Comprendre la responsabilité sociétale de l'entreprise et agir sur les bases de la norme ISO 26000,2011

[17] T. Bansal, "le développement durable en entreprise, Le développement durable en entreprise, c'est contribuer à la prospérité économique, à la santé des écosystèmes et au pouvoir des communautés, 2012.

[18] A. Bernillon, "Implanter et gérer la qualité totale, Les Éditions d'Organisation, 1988.

[19] M. Doucet, "le développement durable dans les PME au Québec : outil de diagnostic de facteurs d'influence et des pratiques mises en œuvre, 2012, https://www.usherbrooke.ca/environnement/fileadmin/sites/environneme nt/documents/Essais_2013/Doucet_M. 15-10-2012.pdf

[20] J. Rollin, Comment les entrepreneurs québécois jonglent-ils avec 
l'intégration des principes de développement durable ? Site de la fondation de

l'entrepreneurship,

http://www.entrepreneurship.qc.ca/developpement_durable

[21] S. Sharma, Managerial Interpretations and Organizational Context as Predictors of Corporate Choice of Environmental Strategy. Acad. Manag. J.43, 681-697, 2000

[22] C. Martinet, "Entreprise durable, finance et stratégie, 2004 https://www.cairn.info/revue-francaise-de-gestion-2004-5-page

[23] S. Lagarde-Dupraz, Questionnaire réalisé par l'Association pour les Pratiques du Développement Durable Apdd, 2000.

[24] D. Lebegue, l'ORSE - (Observatoire sur la Responsabilité Sociétale des Entreprises), 2003.

[25] N.A. Torugsa, O'Donohue,W.; Hecker, R. Capabilities, Proactive CSR and Financial Performance in SMEs:Empirical Evidence from an Australian Manufacturing Industry Sector. J. Bus. Ethics, 109, 483-500, 2012.

[26] L. Lin et al., Financial performance and corporate social responsibility: Empirical evidence from Taiwan. Asia Pac. Manag. Rev, 24, 61-71, 2019

[27] R. Freeman, Divergent Stakeholder Theory, Academy of Management Review, 4, 1999. 